\title{
Algumas observações pragmáticas na construção de sentidos na produção escrita - um estudo de caso bilíngüe
}

\section{Lucia Rottava \\ DELAC/UNIJUÍ}

This study investigates, on a pragmatical perspective, the making of meanings in the written productions of a Portuguese-Spanish bilingual speaker. The subject's mother language is Portuguese. However, he has lived in a context where Spanish is the official language. The data emerge from two written texts produced in different situations. The results suggest that the written productions reflect the social practice in which the subject takes part. They also represent the place where his pragmatical knowledge interacts with the target language. This study contributes to a reflection on the role of the teacher as an interlocutor determined by the institution who seems to be in conflict with the bilingual subject/writer.

Este estudo investiga, sob uma perspectiva pragmática (cf. Thomas,1983 e Mey,mimeo, 1985 e 1993), a construção de sentidos na produção escrita por um falante bilíngüe (cf. Skutnabb-Kangas, 1981 e Romaine, 1995), cujas línguas focalizadas são o português e o espanhol. A língua materna do sujeito é o português, mas esteve em contexto em que a língua oficial é o espanhol. Os dados são dois textos escritos produzidos em situações diferentes. Os resultados sugerem que as produções escritas do sujeito refletem as práticas sociais de que participa e representam o lugar em que seu conhecimento pragmático interage com a língua alvo.

Uma contribuição deste estudo diz respeito à reflexão a respeito do papel do professor como interlocutor institucionalmente determinado que parece estar em conflito com o sujeito/escritor bilíngüe.

\section{Introdução}

Este estudo tem como objetivo analisar, sob uma perspectiva pragmática (cf. Thomas, 1983 e Mey, mimeo, 1985 e 1993), a construção de sentidos na produção escrita por um falante bilíngüe (cf. Skutnabb-Kangas, 1981 e Romaine, 1995) de português e espanhol.

$\mathrm{O}$ sujeito deste estudo, identificado por $\mathrm{RB}$, tem quinze anos de idade, nasceu e viveu no Paraguai até os catorze anos. É filho de pais de classe média baixa - o pai carpinteiro e a mãe dona de casa, ambos analfabetos. RB tem quatro irmãos, sendo três com idade superior e um com idade inferior à dele. Todos os irmãos são nascidos no Paraguai, alfabetizados/escolarizados naquele mesmo contexto.

Atualmente RB mora no Brasil, região muito próxima à zona de fronteira BrasilParaguai; situação que lhe permite 'acesso' e/ou 'contato' com ambas as línguas português/espanhol. As características geográficas da região e a própria situação financeira difícil da família, tornaram-nos migrantes à procura de emprego. 
No Paraguai, em específico na cidade em que morava RB, vivem muitos brasileiros, fato esse que tornou possível um contato freqüente com a língua portuguesa. Em conversa informal, $\mathrm{RB}$ relatou:

Lá é tudo brasileiro / tem que // sabe da família né Daí meus pais começaram a falá / ah:: tudo mundo né / que e geralmente mora bastante brasileiro no Paraguai ... A maioria é brasileiro.

O relato acima mostra que, embora o sujeito estivesse inserido em contexto em que a língua oficial era o espanhol, a língua portuguesa manteve-se majoritária em relação a ela.

Essa especificidade foi portanto característica do contexto de RB. No ambiente familiar e também fora dele, com outros brasileiros que lá residiam, só era falado o português. $\mathrm{O}$ espanhol manifestava-se em outras situações de contato da família e, para RB, passou a fazer parte de seu repertório somente mais tarde, quando da escolarização.

Pela descrição acima, pode-se dizer que a primeira língua ou língua materna de RB foi o português, mesmo encontrando-se ele em um contexto em que a língua oficial era o espanhol. Neste trabalho, entende-se por primeira língua (L1) aquela usualmente falada em casa (no ambiente familiar), com a qual a criança tem seu primeiro contato (cf. Romaine, 1995:19).

Mais tarde, aos oito anos de idade, quando RB foi para a escola, no Paraguai, passou a ter contato formal com o espanhol, sendo alfabetizado nessa língua. $\mathrm{O}$ sujeito freqüentou o ensino formal em escola paraguaia até os catorze anos de idade, ocasião em que concluiu o primeiro e o segundo ciclo do Ensino Fundamental. Portanto, durante a alfabetização de $\mathrm{RB}$, a alternância de exposição à língua - espanhol na escola e português em casa e com brasileiros próximos - foi freqüente e, depois, em decorrência do movimento migratório, é exposto ao ensino formal em português.

No que tange ao ensino formal em português, RB o tem em uma escola estadual no município de Foz do Iguaçu/PR, o que freqüenta atualmente. Nessa escola é oferecido, por sugestão da Secretaria de Educação do Estado, um programa denominado 'Fluxo' Programa de Adequação Idade Série - destinado a alunos que estão fora da idade escolar para freqüentar o terceiro e o quarto ciclo $\left(5^{\mathrm{a}}\right.$. a $8^{\mathrm{a}}$. séries do antigo $1^{\circ}$ Grau) e que tem como objetivo acelerar esses ciclos escolares, o quais podem ser concluídos em dois anos, sendo possível, no final desse período, os alunos matricularem-se no Ensino Médio ( $2^{\circ}$ Grau). O programa é desenvolvido por disciplinas com currículo específico organizado e desenvolvido pela Secretaria de Educação do Estado. À escola cabe o papel de oferecer aos alunos e/ou comunidade espaço físico e professores para as disciplinas.

No contexto escolar atual, é exigido de RB que aja e tenha domínio formal da língua que a escola 'autoriza', sem nenhum tipo de interferência lingüística e interlingüística; por sua vez, para a escola, língua é um conjunto de regras e normas que 'devem' ser seguidas pelos falantes. Porém, nesse caso de região de fronteira, nenhum tratamento ou organização extra-curricular que atenda a essas especificidades é oferecido. Muito pelo contrário, alunos com características similares a RB deparam-se com os mesmos modelos escolares a que são alfabetizados/escolarizados os demais alunos monolíngües. Essa diversidade que poderia ser explorada pela escola, na maioria das vezes, é entendida por esta como um 'grande problema' para a alfabetização, que se estende às séries posteriores, persistindo até mais tarde, como é o caso aqui estudado. Todavia, a escola acredita que o aluno, ao ser exposto à escolarização, passe a usar a língua de modo adequado ou 'correto'. Entretanto, a própria escola não percebe que objetiva atingir um ideal lingüístico, tomando como estratégia para 
atingi-lo, proibir os alunos que usem outra língua ou variedade lingüística no ambiente familiar a não ser aquela 'autorizada' e ensinada no ambiente escolar, sob o pretexto de que a alternância 'atrapalharia' a aprendizagem da língua (cf. Strelow, mimeo). Essa, segundo Grosjean (1982), é uma das crenças dos monolíngües com relação aos bilíngües. No entanto, a língua para RB simboliza sua identificação sócio-cultural com base em uma configuração lingüística que é utilizada até onde suas condições permitem e de acordo com os diversos propósitos e interlocutores com os quais se comunica.

Uma das crenças negativas sobre o bilingüismo, por exemplo, segundo Grosjean (1995:262), diz respeito ao fato de os aprendizes serem expostos a outra língua somente mais tarde (na adolescência ou fase adulta), dificilmente podendo alcançar um nível de proficiência equivalente a um falante nativo letrado.

Um dos problemas considerados críticos pela escola, com alunos desse contexto e com tais especificidades é a produção escrita. Entretanto, não basta apontar os problemas lingüísticos que se apresentam nessas produções, mas levar em conta que, no processo de construção de sentidos na língua-alvo, o aluno utiliza-se de hipóteses diversas que são levantadas durante a produção escrita. Um dos aspectos considerados neste estudo são as especificidades advindas do uso da língua numa perspectiva pragmática (cf. Mey, mimeo).

Estas questões problematizadas auxiliaram a formular a pergunta de pesquisa na forma que segue abaixo

'como o sujeito expressa/constrói sentidos na produção escrita e como seu interlocutor (escola/professor) concebe tal produção?'

Para responder à pergunta acima, os dados serão analisados buscando mostrar as razões que tornam a produção de $\mathrm{RB}$ inadequada face à perspectiva da escola.

\section{Considerações teóricas}

\subsection{Considerações a respeito do bilingüismo}

Uma pergunta inicial passa a ser pertinente ao se tratar de um trabalho que envolve um falante exposto a duas línguas, ou seja, o que é ser bilíngüe? Que critérios deverão ser tomados para definir uma situação de bilingüismo como a descrita acima? Para responder a algumas dessas questões, a literatura da área tem levado em conta alguns aspectos, principalmente, os que dizem respeito ao modo pelo qual o falante está exposto à(s) língua(s), e a origem geográfico-social do bilíngüe, de modo a entender suas especificidades. Contudo, são necessárias mais pesquisas com o propósito de aprofundar tais usos.

Genericamente a literatura da área nos diz que bilingüismo é o uso alternado de duas línguas por parte de um mesmo falante. Esse uso é, segundo Grosjean (1995:259), uma configuração lingüística específica de um falante-ouvinte que usa uma das línguas dependendo do contexto e dos interlocutores, como também de acordo com as suas necessidades. $O$ fato de usar esse conceito elimina implicações do tipo: o que seria um bilíngüe proficiente? Se ele somente compreende e não produz, se é um bilíngüe passivo ou não e em que estágio ele se encontra (cf. Boutet e Vermes, 1989). Entretanto, Romaine (1995:7) faz ponderações a respeito de se delimitar um conceito tácito para bilingüismo, pois segundo ela, o bilingüismo é um recurso a ser cultivado, não um problema a ser eliminado. $\mathrm{O}$ fato de se falar mais de uma língua deve ser visto com outros 'olhos' e 
atitudes, os quais valorizem as pessoas que tornam o bilingüismo verdadeiro ${ }^{1}$ de uma perspectiva individual e/ou coletiva.

O que caracterizaria o sujeito aqui focalizado? Para explicitar esse aspecto recorri novamente à literatura, procurando identificar os tipos bilíngües. Romaine (op.cit.12) sugere que há quatro questões que numa descrição de bilingüismo poderiam ser focalizadas (grau, função, alteração e interferência), como também há diversas tipologias de bilíngües, podendo ser observadas de um ponto de vista psicológico ou cognitivo, e inclui-se ainda fatores internos e externos (cf. Weirinch, 1968 e Skutnabb-Kangas, 1981). Os fatores internos incluem, por exemplo, a atitude, a motivação e a idade. Os externos dizem respeito à duração e à freqüência do contato com a língua, em quaisquer situações, tais como casa, comunidade e escola, dentre outros contextos.

Qual a influência dos fatores externos para tornar um falante bilíngüe? Os fatores externos são determinados pelo contato, pela variação, duração e freqüência que o falante tem com a língua-alvo. Esses fatores, predominantemente, concretizam-se no contexto familiar, escolar e social (grupo de amigos).

Do ponto de vista psicológico podemos ter um falante bilíngüe que possui a mesma competência em ambas as línguas ou que tem competência diferente em cada uma das línguas. Se o falante apresentar a mesma competência é considerado bilíngüe equilibrado, mesmo que empregue essa competência com interlocutores, contextos ou funções distintas. Se, por outro lado, apresentar competência diferente é considerado bilíngüe desequilibrado, pois um sistema predomina em relação ao outro, podendo inclusive influenciar ou interferir no sistema menos desenvolvido. Contudo, uma competência maior ou menor em uma língua não se distribui da mesma maneira em todas as situações comunicativas a que se está exposto.

Com relação ao desenvolvimento da representação lingüística como um sistema único ou separado, a literatura nos mostra que tal desenvolvimento ocorre de modo que os dois sistemas sejam distintos (bilíngüe coordenado) ou a aquisição dos dois códigos tenha lugar como uma representação comum a ambos os sistemas (bilíngüe composto). Nesse sentido, Weinreich (1968) sugere que o bilíngüe pode conceber apenas um conceito para dois significantes diferentes, ou possuir dois significados distintos para dois significantes equivalentes, ou ainda considerar os referentes dos signos de uma língua aprendida como equivalentes aos da língua já dominada.

Outra questão que deve ser considerada para a determinação do tipo de bilingüismo é a idade. Conforme a idade de aquisição/desenvolvimento dos sistemas, pode-se ter o bilíngüe precoce, adolescente ou adulto. Os casos de bilingüismo precoce são representados por crianças que adquirem as duas línguas ao mesmo tempo e antes dos cinco anos de idade. Porém, o fato de relacionar bilingüismo com idade não é uma opinião convergente entre pesquisadores da área (cf. Boutet e Vermes, 1989), pois o bilingüismo precoce seria também aquele que é representado por crianças provenientes de casamentos mistos, em que cada um dos pais só falaria em sua própria língua materna.

Além disso, há situações em que as crianças passam a morar no exterior, em decorrência de os pais migrarem para trabalhar ou estudar; em princípio, predomina a

\footnotetext{
${ }^{1}$ Estou referindo-me a muitas situações em que descendentes de imigrantes (italianos e alemães, em particular no Sul do Brasil) buscam manter viva suas raízes, seus costumes, sua língua através de festas e/ou comemorações (por exemplo, Oktoberfest, Festa da Uva).
} 
língua dos pais, mas progressivamente toma lugar a língua do país em que vivem por meio do contato com amigos, vizinhos, mídia, dentre outros. Essa é uma situação denominada de bilingüismo precoce sucessivo.

Finalmente, quando a criança adquire outro sistema durante a infância, porém após ter ocorrido a aquisição da primeira língua, na educação básica ou letramento, teríamos um caso de bilingüismo sucessivo. No caso de RB, a aquisição resultou das situações formais e de sala de aula, sendo, portanto, sucessivo.

Além dos aspectos cognitivos e psicológicos, um outro fator fundamental diz respeito ao status do bilíngüe enquanto falante de uma língua $\mathrm{X}$ ou $\mathrm{Y}$ que é determinado pelo grupo a que ele pertence. Dentre esses grupos, podem-se perceber diferenças que marcam falantes bilíngües como pertencentes a grupos minoritários ou privilegiados que são representados pelos falantes da língua majoritária. Os que têm privilégios sociais também têm privilégios lingüísticos, distinguindo-se dos demais quanto ao acesso a outra língua, à cultura e ao sucesso de sua aprendizagem. Nesse sentido, o fato de ser bilíngüe é um ponto positivo, servindo como um degrau de ascensão social.

Em outro extremo, os falantes de grupos minoritários, ao contrário dos demais, sofrem discriminações de diversas ordens, não somente lingüísticas mas sociais e econômicas, decorrentes das condições a que foram e são expostos à língua e à sociedade. A esses grupos, tanto o acesso quanto o contato com uma outra língua ocorre de modo circunstancial, devido às próprias condições ou necessidades de sobrevivência da família que, na maioria das vezes, desloca-se de um lugar para outro em busca de meios para sobrevivência. Essas situações são típicas de regiões de fronteiras geográficas e lingüísticas ${ }^{2}$, como nesta pesquisa.

Finalmente, a última questão diz respeito ao modo como determinar o grau de bilingüismo. Quanto a esse ponto, uma das observações possíveis no que diz respeito ao grau de bilingüismo é levar em conta o conceito de competência comunicativa em uma das línguas. O conceito de competência comunicativa foi primeiro desenvolvido por Canale e Swain (1980) e Canale (1983), sendo composto minimamente pela competência gramatical $^{3}$, sociolingüística ${ }^{4}$ e por estratégias de comunicação ou competência estratégica ${ }^{5}$, e deve responder às necessidades básicas de comunicação do aprendiz, oportunizando-lhe tomar parte na interação significativamente comunicativa com falantes nativos da língua.

Contudo, em se tratando de situação de bilingüismo, estão implicados outros conceitos quando é abordado o termo competência, denominados de mudança ou mistura,

\footnotetext{
${ }^{2}$ Penso aqui como seria esse contato numa região de fronteira somente geográfica mas não lingüística, como é o caso de Uruguai e Argentina ou Paraguai, sem ser, entretanto, o caso do Brasil.

${ }^{3}$ Competência gramatical - este tipo de competência diz respeito ao conhecimento de itens lexicais e de regras de morfologia, sintaxe, semântica e fonologia.

${ }^{4}$ Competência sociolingüística - Este componente é organizado a partir de dois conjuntos de regras: regras socioculturais de uso e regras de discurso. Conhecer essas regras será crucial para interpretar enunciados quanto ao seu significado social, particularmente quando há um baixo nível de transparência entre o significado literal de um enunciado e a intenção do falante.

${ }^{5}$ Competência Estratégica - este componente é constituído de estratégias de comunicação verbal e não verbal que poderiam estar dentro da ação para compensar uma quebra na comunicação devido a variáveis de desempenho ou competência insuficiente. Tais estratégias podem ser de dois tipos: aqueles ligados primeiramente à competência gramatical e aqueles ligados à competência sociolingüística.
} 
quais sejam, mudança de código ${ }^{6}$ (code-switching ou code-mixing) ou empréstimos ${ }^{7}$. Essas mudanças são, genericamente, denominadas por 'mistura' (mixing) ou por 'falha/fracasso' (failure).

Uma 'mistura', segundo Romaine (1995:124), pode ser compreendida como um termo neutro que engloba os códigos e/ou as línguas, em que o falante usa ora uma língua ora outra, independente da situação comunicativa.

Por sua vez, uma 'falha/fracasso' (failure) pode ser observável na concretização do objetivo comunicativo (cf. Thomas, 1983), pois pode ocorrer que esse objetivo não seja alcançado por não estar claramente posto para o falante qual o propósito, seu interlocutor ou ainda, não ter claramente explícito o contexto de que se trata em uma dada situação de comunicação.

Os termos 'mudança' tomado por Romaine (op.cit:121-179), e falha/fracasso, tomado por Thomas (op.cit), foram discutidos e analisados sob duas perspectivas, ou seja, sob a perspectiva gramatical e pragmática. A gramatical é tratada via termos restritos à estrutura lingüística das sentenças. A pragmática trata via termos mais amplos, isto é, enquanto fenômeno de uso que não pode ser satisfatoriamente tratado em termos da estrutura lingüística das orações. $O$ foco de análise neste trabalho é a perspectiva pragmática da produção escrita. Antes, porém, é necessário definir o que é compreendido por pragmática.

\subsection{Considerações a respeito da pragmática}

A pragmática é o estudo da linguagem em uso (na comunicação) que envolve a compreensão de como e por que o contexto social influencia a produção dos enunciados ${ }^{8}$ (cf. Mey, 1985). Em outras palavras, um estudo de cunho pragmático visa investigar as relações estabelecidas entre usuários e contexto na comunicação. Portanto, levar em conta o uso da linguagem ligada ao conhecimento do usuário, a relação falante/ouvinte (leitor/escritor) e o contexto de uso é, também, considerar como esse 'uso' é socialmente determinado.

No contexto social, a própria formação social define os usuários de uma língua. Essa constituição pode ser visualizada no esquema que segue:

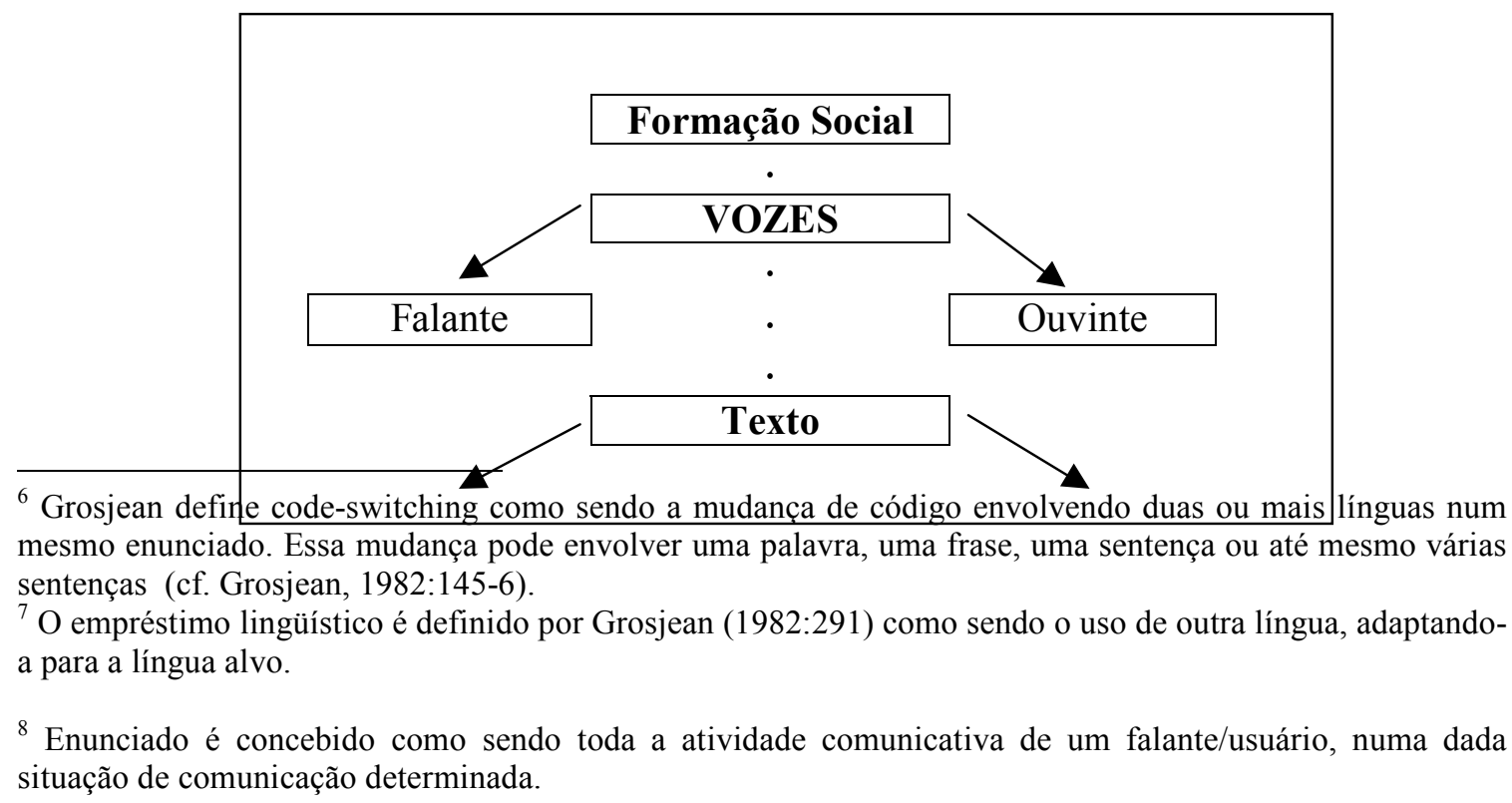


Uma formação social, segundo Mey (mimeo), consiste num espaço social criado por vozes que operam nele próprio. O termo voz é utilizado por esse autor para designar qualquer atividade no uso da linguagem.

As vozes pressupõem um papel - linguagem em uso -, de acordo com o que pode ser dito em uma língua, em termos de atividades ou ações de que seus membros (falantes/ouvintes) participam.

O falante, usuário de uma língua, constituiu-se numa situação em que dois ou mais pares conversam, cada qual buscando contribuir da melhor maneira para o tópico que está sendo tratado. Nessa mesma situação, é constituído o ouvinte - interlocutor -, não reduzido ao desempenho de uma mera reação mecânica do que ouve, mas a partir de um princípio que direciona as vozes de uma dada formação social, isto é, vivencia realmente uma prática social de uso da linguagem, não somente como receptor daquilo que o falante tem a dizer, mas também tem o que dizer numa ação que se constitui em um tipo de confrontação (cf. Mey, mimeo), em que as vozes são ouvidas e vivenciadas.

Essas vozes, portanto, seriam resultantes da confrontação, pois em toda e qualquer comunidade social elas não são uníssonas. Para as vozes serem ouvidas na sociedade depende do papel social que o falante/ouvinte desempenha.

A organização das vozes na sociedade difere em formas e padrões de produção e reprodução. Uma dessas formas ou padrões é o 'texto' escrito - uma organização coletiva de vozes (orais e escritas) que envolvem a totalidade das práticas que compõem a vida cotidiana de uma sociedade.

Assim, como as vozes na formação social (falantes/ouvintes) não são produzidas ou entendidas num 'vácuo', porque dependem de um certo status por parte de seus usuários, as vozes do texto também envolvem o papel de seus usuários - escritores/leitores - na formação social.

No texto, há inúmeras formas de se ouvir a voz da sociedade, particularmente pela capacidade que seus usuários possuem para ler e escrever. Essa capacidade de uso na língua é denominada na literatura de 'letramento'. Embora esse termo não seja ainda claramente definido, ele designa um conjunto de práticas sociais cujos modos específicos de funcionamento têm implicações importantes para as formas pelas quais os sujeitos envolvidos nessas práticas constróem relações de identidade e de poder (cf. Kleiman, 1995:11).

$\mathrm{Na}$ escola, entretanto, as práticas sociais de leitura/escrita têm sido entendidas como sinônimo de alfabetizar (cf. Tfouni, 1995 e Soares, 1998). Ler e escrever enquanto prática está muito mais ligado à idéia de letramento. Por sua vez, a diferença entre esses dois termos requer que se entenda que alfabetizar significa apenas a ação de ensinar/aprender a ler e a escrever, enquanto letramento diz respeito à condição de quem não apenas sabe ler e escrever, mas cultivar (dedicar-se a atividades de leitura e escrita) e exercer (responder às demandas sociais também dessas mesmas habilidades) as práticas sociais que usam a escrita. Nesse sentido, cabe ressaltar o fator limitante de não ser desenvolvida na escola a leitura e a escrita enquanto práticas, pois ao ser colocado que a escola alfabetiza acreditando estar expondo os alunos à prática da leitura e da escrita, na verdade o que está fazendo é 'treinando-os' a simplesmente decodificarem um material escrito. Sem dúvida, em 
sala de aula estão refletidas certas normas e valores institucionais, mas não da dimensão mais ampla de sociedade a que a escola pertence.

Portanto, as práticas sociais perpassam o uso da língua pelo bilíngüe e devem também perpassar as práticas de letramento que a escola leva adiante em sua tarefa de ensinar a ler e a escrever.

Da perspectiva do texto escrito produzido por um falante bilíngüe são levadas em conta para sua análise, além dessa visão de letramento, as formas e estruturas presentes no texto, direcionando a atenção em alguns conceitos psicológicos, tais como: conhecimento e experiências anteriores, crenças e expectativas.

Embora os estudos na área de bilingüismo no que tange à produção escrita enfoquem a construção de sentidos em termos de 'mistura de códigos', o foco nesta pesquisa está direcionado à produção escrita sob a perspectiva pragmática (cf. Mey, 1985, 1993 e mimeo; Thomas, 1983), procurando 'olhar', através do produto escrito, o uso da língua por $\mathrm{RB}$, ou seja, que práticas sociais o falante vivencia.

Como mencionei anteriormente, mudança ou mistura de código podem decorrer de fatores pragmáticos envolvidos no uso da língua feita pelos falantes bilíngues ao se referirem a um propósito e a um interlocutor, isto é, ao efeito comunicativo que pretendem concretizar. Assim, os falantes constróem 'uma imagem' de si e a de seus interlocutores para produzirem uma informação sobre o modo como pretendem ser compreendidos. É nesse sentido que, ao analisar a produção escrita, é necessário se considerar a força pragmática que um determinado item gramatical pode tomar e o efeito do sentido produzido. Portanto, é uma visão que prioriza um continuum entre o uso da língua concretizada via texto e a intenção do falante na tentativa de construir sentidos na língua a que se está exposto.

\subsection{Estudos feitos nesse contexto}

Os estudos feitos no contexto ora descrito incluem somente considerações lingüísticas que envolvem essas duas línguas próximas. Em estudo realizado por Strelow (mimeo) com um grupo bilíngüe de alunos de $1^{\mathrm{a}}$. a $3^{\mathrm{a}}$. séries do Ensino Fundamental, os resultados mostraram que a produção escrita sofre interferências fonéticas e/ou fonológicas (g por $\mathbf{j}$ e u por $\mathbf{l}$, por exemplo), trocas em ambiente intervocálico anteposto da vogal 'e' e 'o' (p.17-19), decorrentes da equivalência sonora existente entre os sistemas do português e do espanhol. Dessa forma, o trabalho de Strelow (op.cit.) mostrou uma situação comum/típica da região, como a descrita para o caso de $\mathrm{RB}$.

Muito embora o trabalho de Strelow (op.cit) enfoque somente esse aspecto, muitos outros podem ser observados nos dados do mesmo (questões fonológicas: trocas de vogais anteriores; morfológicas: pido por peço, dentre outras).

Outros trabalhos feitos em contexto de línguas próximas consideraram as interferências que ocorrem tanto na fonologia quanto na morfologia, na sintaxe e no léxico (cf. Lombello, 1983; Lombello, El-Dash e Balleiro, 1983; Jordan, 1991:789-791; Hoyos Andrade, 1996 e Viciano, 1996:43). Os aspectos fonológicos dizem respeito às interferências motivadas pelas diferenças ción/ção ou por aquelas que apresentam algumas possibilidades de semelhanças, como por exemplo o ll em espanhol pode tornar-se $\mathbf{c h}, \mathbf{l}, \mathbf{p l}$, pr em português - llave/chave, ella/ela, llano/plano e llano/pranto (cf. Jordan, 1991:780). Esse autor aponta também para o uso inadequado de ue/o (muerte/morte), ie/e (tierra/terra) em que aprendizes de português encontram dificuldades e, ao tentar saná-las, acabam 
fazendo uma hipercorreção ${ }^{9}$ de uma regra que é específica da L1 (cf. Takeuchi, 1984). Os aspectos morfo-sintáticos incluem as formas verbais e categorias gramaticais: pronomes, conjunções, além das preposições, gênero dos substantivos (a computadora /o computador), uso inadequado de reflexivos (morrer-se), colocação pronominal e o uso de articuladores/conectores lógicos, por exemplo: como e assim, dentre outros.

Finalmente, há formas semelhantes observadas no léxico que podem ser compreendidas como semelhança de significado, acarretando problemas de compreensão. Por exemplo, acebollado em espanhol, diz-se da madeira defeituosa quando duas camadas apresentam algum tipo de separação e, acebolado em português refere-se ao que tem sabor de cebola, condimentado/temperado com cebola. Também, a palavra calar, que em espanhol significa encharcar e, em português, significa deixar de falar, estar ou ficar em silêncio. Proximidades de formas e diferenças no significado que podem gerar inadequações que, por um lado, ajudam na compreensão e produção de sentidos, por outro, representam inapropriações no uso da língua (cf. Rottava, 2001).

Com base no exposto acima, observa-se que esta é uma situação peculiar do ponto de vista das relações interculturais e extremamente complexa do ponto de vista lingüístico em nível formal na construção de sentidos adequados. Por essa razão, é interessante investigar que aspectos podem ser observados na produção escrita, decorrentes das especificidades e das experiências de um aprendiz neste contexto.

Entretanto, é necessário explicitar o conceito de produção escrita que é tomado neste estudo. Parto da perspectiva da produção escrita como processo, visto que, enquanto processo, ensinar a escrever é considerar o ciclo de toda a atividade de compor. A ênfase centraliza-se naquilo que os sujeitos fazem enquanto compõem, não em um resultado final, mas incluindo as várias versões e, portanto, sendo vista como não linear (cf. Zamel, 1992). Além disso, escrever é uma atividade que tem como pressuposto que os escritores centramse primeiro no conteúdo e deixam detalhes de forma para mais tarde; essa mesma produção escrita tende a melhorar quando ela resulta da preocupação com o que está sendo comunicado para seu leitor, isto é, quando o escritor sabe para que e por que escreve e quem é o seu leitor/interlocutor (cf. Rottava, 2001).

Nessa perspectiva, ao ser levado em conta o 'uso adequado' da língua, por conseguinte, especificamente em contexto bilíngüe, a produção escrita pode variar de acordo com os tipos de textos ou contextos com que os aprendizes se deparam em seu cotidiano. Essas particularidades incluem o funcionamento da língua naquele contexto, incidindo nele as atitudes, os interlocutores e o prestígio social dos seus falantes sem, entretanto, deixar de produzir sentidos. Não se fala ou se escreve para preencher espaços em branco, mas tem-se um objetivo e/ou propósito. Portanto, se essas especificidades e características do aluno bilíngüe forem levadas em conta no momento de se proporem tarefas ou atividades para que ele as desempenhe, a atividade de produção escrita lhe será mais significativa.

\section{Apresentação e análise dos dados}

\subsection{Os dados para a análise}

Os dados para esta análise foram coletados por meio de uma entrevista individual aberta feita pela pesquisadora com o sujeito, e de dois textos escritos produzidos em

\footnotetext{
${ }^{9}$ A hipercorreção é o processo pelo qual ao ser aprendida um regra ela passa a ser usada em contexto que não é apropriado.
} 
situações diferentes: o primeiro (T1) foi produzido em sala de aula, resultante de uma tarefa na aula de língua portuguesa. $O$ texto é de gênero narrativo e não foi informado pela professora qual foi a proposta que resultou na produção ${ }^{10}$. O segundo (T2) foi coletado em situação de pesquisa, quando solicitado a RB que produzisse um texto de gênero informativo, a partir da seguinte instrução proposta oralmente pela pesquisadora: 'escreva sobre alguma coisa que você gosta para seus amigos da escola, dizendo por que você gosta; por exemplo, se você gosta de um programa na televisão, o que prefere fazer ou se gosta ou não da cidade em que você mora, justificando'. O objetivo era obter um segundo texto para observar se o gênero ${ }^{11}$ influenciava a produção do texto.

Tanto a produção do T1 quanto do T2 apresentam elementos que permitem explicitar a organização e a produção de sentidos na língua alvo. Produzir sentidos nessa modalidade não é somente dominar as formas físicas das letras, ortografia e pontuação, mas também os padrões estruturais e organizacionais que caracterizam a escrita. É, portanto, sobre esses aspectos que comento a seguir.

\subsection{A construção dos sentidos na produção escrita}

Retomando a pergunta de pesquisa

'como o sujeito expressa/constrói sentidos na produção escrita e como seu interlocutor (escola/professor) concebe tal produção?'

Para responder à questão acima, recorro aos dois textos (T1 e T2) produzidos por $\mathrm{RB}$, os quais retratam as experiências e as expectativas do sujeito/escritor vivenciadas no contexto no qual está inserido, bem como revelam a própria identidade do sujeito, resultante da convivência com mais de uma língua.

Ambas as produções de RB refletem um evento de escrita de acordo com o conceito de letramento, isto é, produções que refletem as práticas sociais com as quais tem algum contato. Provavelmente, produções que não atendem às expectativas de um modelo escolar que não considera as práticas sociais. Inicio a análise pelo T2 por ser o mais recentemente produzido.

Nesse texto, a produção revela um pouco da história de RB, evidenciada no trecho:

(01) Foz do Iguacu geralmente eu estou morando aqui en foz a pouco tempo eu gosto dos colegas que tenho aqui e das cataratas do Iguacu (1.1-3)

no exemplo, pode-se observar que a produção escrita do sujeito é construída a partir do que lhe é significativo e daquilo que vivencia no cotidiano, como uma maneira de dizer/falar sobre seu mundo e de tornar sua voz presente com a expectativa de que ela seja ouvida. $\mathrm{Na}$ produção escrita, a voz do sujeito revela que, além de trazer o que lhe é significativo, também organiza o texto, pois introduz o evento fazendo menção no título, atualiza o contexto situacional da produção, co-ocorrendo com o seu contexto real e dá continuidade a ele, situando quem é seu leitor e/ou interlocutor. Perpassam, assim, logo na inicio da

\footnotetext{
${ }^{10}$ O T1 foi considerado pela escola como um 'mau exemplo' de produção escrita, pois o mesmo apresenta grande quantidade de erros e problemas formais. Razão essa que levou a professora a solicitar ajuda externa para entender o que estaria ocorrendo com esse sujeito para produzir do jeito que produz.

${ }^{11}$ Gênero é entendido como sendo um evento comunicativo com propósito e interlocutores definidos (cf. Swales, 1990 e Tribble, 1996).
} 
produção, as manifestações dos pensamentos e experiências relativas ao ambiente vivido por RB, enquanto autor da própria produção.

Do ponto de vista lingüístico da organização do trecho acima exemplificado, após RB mencionar, no título, o tópico que irá tratar, retoma-o mantendo a referência ao tópico. Essa retomada é visualizada por meio da ocorrência do uso do advérbio aqui (1.1), seguindo-se a repetição do substantivo foz (1.1), novamente sendo usado o mesmo advérbio (1.1); além disso, utiliza-se do termo cataratas do Iguacu (1.3) para designar uma qualificação local. Tais recursos lingüísticos mostram que o sujeito tem conhecimento ou domínio da língua (porém não aquele esperado pela escola, uma vez que esta prevê tal domínio de acordo com as regras do sistema da língua-alvo) ou de seus recursos formais necessários para a produção, pois sugere, via texto, que sabe como utilizá-los para fazer com que sua $v o z$ - ao mencionar um lugar típico que é de conhecimento compartilhado com $\mathrm{o}(\mathrm{s}) \mathrm{seu}(\mathrm{s})$ interlocutor(es)/leitor(es) - esteja presente na produção. Entretanto, como já mencionei, essa voz não é reconhecida pela escola, pois esta reconhece somente a voz que está de acordo com as regras formais da língua-alvo.

Além do conhecimento e/ou experiências de mundo do sujeito traduzidas em vozes e concretizadas na produção escrita, elas fazem emergir as expectativas de RB com relação ao contexto social de que participa; essas, por sua vez, são reveladas quando é deixado explícito pelo sujeito seu ponto de vista a respeito da comunidade em que está inserido, como em

(02) ... acho una coisa muito natural e escresivamente simples o geito que os jovens curten a vida ... (1.3 - 5)

ou seja, a voz do sujeito (ainda adolescente) traz suas experiências para dentro do texto, descrevendo o evento e complementando-o com a descrição do local, das pessoas de seu convívio e do(s) ambiente(s), ou seja, revela a formação social característica e a comunidade de que participa.

Para além do exposto acima, essas mesmas vozes fazem emergir as expectativas e desejos próprios do escritor na produção escrita, como em

(03) ... de me divertir de outra forma esemplo. se reunir com os amigo un fin de semana en mia casa para esprêsarmos o momento da vida. (1.6-9)

ou ainda no trecho

(04) E assim que eu vejo a vida como ela e. O que vai vir eu simplesmente vou aseitar (1.27-29)

conclui-se, pelos exemplos (03) e (04) que a voz do sujeito é revelada na produção escrita por ecoar sua formação social.

Passo, no que segue, a comentar o T1. Nesse texto, igualmente ao acima analisado ecoa a voz do sujeito, que, através da produção escrita, permite-lhe vivenciar um outro mundo, particularmente diferente do seu. Esse mundo diferente é decorrente de uma formação social a que possivelmente deseja pertencer; um mundo de fantasia que, na maioria das vezes, não é de acesso às classes minoritárias. Para mostrar ou sinalizar tal exclusão, RB produz a partir de uma perspectiva externa desse contexto, como em 
un dia en uma fazenda viviam un casal

de velinhos e una jovenzinha é essa garotinha (título e 1.1-2)

Percebe-se porém, que embora o modelo descrito seja aquele da formação social - familiar-, evidenciam-se nele conflitos, possivelmente iguais aos do próprio escritor:

(06) ...nâo tinha una amiginha para brincar é ate mesmo pasear a cavalo. entâo a garotinha converso muito com os seu avós e até mesmo começou a falar de coisas que nei o seu avos havia le dito... (1.5-8)

Possivelmente, o mundo descrito não é aquele de que RB, como muitos outros de classes minoritárias, faz parte, mas que faz emergir, via produção escrita, as expectativas e/ou desejos de tal.

Igualmente à produção escrita anteriormente analisada, nesta também o sujeito mostra uma certa familiaridade com a modalidade escrita. $\mathrm{O}$ T1 é produzido sob o gênero narrativo, em que o sujeito dá continuidade de modo coerente ao foco, ou seja, introduz, desenvolve e dá um final); contudo, a escola - interlocutora e leitora das produções de RB, considera seus textos como problemáticos, pois não são realizados seguindo as regras formais de uso da língua-alvo e, por essa razão, os textos não respondem às expectativas da escola quanto ao critério que os contempla como sendo 'corretamente' produzidos, de acordo com as normas requeridas na modalidade escrita.

As incoerências sinalizadas pela escola envolvem, por exemplo, os marcadores utilizados nas produções, particularmente na sobreposição das idéias e na sua consecutividade. No T2, por exemplo, os marcadores foram usados com base no uso aleatório de sinais da pontuação, principalmente de vírgula (1.9) e pelo uso da conjunção e $(1.10,13,22,23,25$ e 26, dentre outros). Entretanto, RB demonstrou saber lidar com alguns recursos próprios da escrita. Exemplos podem ser observados pelo uso de marcadores lógicos, representados por até mesmo (1.07 e 53), de repente (1. 10, 15 e 34), então (1.11, 20,21 e 23) e por isso (1.53), muito embora o uso de então possa ser caracterizado como uma marca de oralidade presente na produção escrita. Esse marcador, sobretudo, viabiliza a seqüencialização de uma informação ou de uma ação a ser apresentada. O exemplo (07) mostra isso:

(07) (...) tudo se acalmou então ela penso (1.11)

Tais colocações, tanto no T1 quanto no T2, partem da observação de que a produção escrita de RB apresenta características da experiência e das expectativas do uso que é feito da língua para construir sentidos na escrita, diferentemente do seu uso no cotidiano. RB vale-se de traços da produção oral para tornar sua prática social de escrita mais real, bem como para desenvolver as idéias postas nas produções. Segundo Perera (1990:261), é no desenvolvimento das idéias que é dado um propósito ao texto. Todavia, esse propósito, do modo como RB concretizou-o na modalidade escrita, não está adequado à norma escolar, pois para esta, o que ocorreu na produção escrita, enquanto seqüência argumentativa das idéias expostas pelo sujeito, constituiu-se em um mero 'jogo de conseqüências' ${ }^{12}$, isto é, o

\footnotetext{
${ }^{12}$ Um jogo de conseqüências consiste em cada informação nova colocada no texto ser uma conseqüência de uma causa imediatamente anterior à exposta no texto. Na verdade é uma sucessão de causas e conseqüências localizadas no interior do texto, sem entretanto, constituir o tema central do texto.
} 
sujeito/escritor apenas adiciona um conjunto de idéias que têm conseqüências entre si para desenvolver o tema.

Em contrapartida, se a produção escrita for vista como um evento comunicativo (Swales, 1990) que tem o que dizer e realmente o diz, essas idéias se concretizam, por exemplo no T1, quando da (a) apresentação do personagem (1.01 a 14), (b), ação (1.15 a 18), (c) conseqüências dessa ação (1.18 a 33) e, por fim, (d) conclusão, evidenciando uma voz que tem uma lição a ser aprendida pelo leitor, por meio do evento descrito (1.34 até o final). Essa mesma dinâmica é observada no T2, no relato do evento (introdução de dados do local (1.1-3), das ações que nele ocorrem (1.4-23)), evidenciando seu ponto de vista (faz ecoar sua voz (1.24-29)), igualmente às práticas de uso da linguagem a que RB pertence, dada sua formação social. Os textos, desta forma, refletem tais vozes.

Portanto, em ambos os textos, observa-se que a construção de sentidos inclui a necessidade de haver, além de uma coerência global dos sentidos uma coerência interna do evento. RB, em T1, traz essa coerência ao interagir por escrito no interior do texto, mostrando uma produção que se constituiu e resultou da prática que o identifica como tal, defrontando-se com dificuldades - do ponto de vista da escola, uma produção inadequada de acordo como ponto de vista das regras e normas da língua alvo. Em T2, a coerência é também instituída pela inserção do sujeito no evento que é produzido.

As produções de RB apresentam características da interação face-a-face, contendo uma descrição da situação por meio de idéias justapostas. Desse modo, há uma 'voz' que reflete o 'dito' pelo sujeito/autor; todavia, essa 'voz' é compreendida pela escola como uma inadequação à modalidade escrita. Tal inadequação é atribuída pelo fato de ser bilíngüe (cf. Edelsky, 1986) $)^{13}$, quando na realidade ser bilíngüe não é uma limitação nem necessariamente indica falta de conhecimento por parte do sujeito, mas pelo fato de não lhe ser propostas atividades que requeiram uso da linguagem em situações comunicativas e significativas para os sujeitos.

\section{Conclusões e considerações complementares}

Concluiu-se pela análise das produções escritas de RB, que o uso feito da língua representou o lugar em que seu conhecimento pragmático interagiu com a língua alvo, muito embora os aspectos lingüístico-gramaticais não estarem de acordo com as regras formais da língua, as quais a escola espera que os alunos absorvam de imediato e usem de modo adequado à modalidade escrita.

As práticas de letramento têm sido ignoradas pelas escolas, particularmente naquela em que RB se encontra, preferindo trabalhar numa perspectiva gramatical, cujas regras são fixas e apresentam um grande nível de precisão na descrição da competência. A sugestão seria uma prática que levasse com conta o uso da língua em seus mais diversos contextos, em que principalmente sejam dadas aos alunos oportunidades para se constituírem enquanto sujeitos ativo do processo de construção de sentidos.

Na perspectiva de letramento, a construção de sentidos na modalidade escrita não se traduz em uma dificuldade ou em diferença lingüística que diz respeito tão somente ao

\footnotetext{
${ }^{13}$ Edelsky nesse texto fala dos mitos que são atribuídos ao falante bilíngüe quanto ao uso da língua, especificamente em se tratando da produção escrita. Esses mitos estão ligados as crenças de que as crianças bilíngües: (a) fazem trocas lingüísticas muito freqüentes; (b) possuem um vocabulário restrito; (c) não pressupõem interlocutores e nem organizam seu texto dependendo dos diferentes propósitos; (d) produzem erros aleatórios, dentre outros.
} 
domínio da escrita, mas no próprio uso da linguagem de acordo com a formação social de seu usuário. É importante e relevante que, ao produzir um texto, o sujeito tenha algo sobre o que escrever, necessitando um objetivo e um possível interlocutor que leia o que ele produziu, dando assim, uma característica real ao processo. Além disso, é importante contrapor um propósito de aprender língua em sua modalidade escrita às variações de uso da mesma; variedades essas associadas às diferenças geográficas e lingüísticas.

$\mathrm{O}$ interlocutor, na maioria das vezes, é o próprio professor que desempenha um papel de 'corretor' do produto final da produção escrita, sem entretanto, excluí-lo da função de intervir construtivamente durante o processo, de modo a saber quais os problemas de produção o aprendiz apresenta durante esse processo e quais dificuldades lingüísticas estão associadas ao papel que esse sujeito desempenha na formação social.

Uma sugestão de novas pesquisas poderia envolver o esclarecimento do papel do professor como interlocutor institucionalmente determinado. Esse papel parece estar em conflito, como mostra esta pesquisa, isto é, sujeito/escritor bilíngüe versus escola, envolvendo um sujeito bilíngüe que tem experienciado o uso da linguagem em contexto de L1 e de L2/LE, mas que não domina as regras e normas da língua a que está sendo exposto conforme a escola exige. Por outro lado, tal interlocutor - a escola, lê as produções somente com vistas às normas e às regras da língua-alvo, bem como as regras impostas pelo sistema escolar. Nessa dicotomia, instala-se o conflito pelo fato de o sujeito não preencher os padrões previstos e, por isso, ser exposto ao ensino 'especial' (dado pelo programa do Secretaria Estadual de Educação de adequação idade versus série), como sendo um aluno 'diferente' dos demais.

\section{Referências Bibliográficas}

BOUTET, J.; VERMES, G. Multilingüismo. Campinas: Ed. da Unicamp, 1989. 291p.

CANALE, M. From communicative competence to communicative language pedagogy. In: RICHARDS, J.; SCHMIDT, R. (Ed.). Language and Communication. London: Longman, 1983. p.2-21.

CANALE, M.; SWAIN, M. Theoretical bases of communicative approaches to second language teaching and testing. Applied Linguistics, v. 1, n. 1, p. 01-47, 1980.

EDELSKY, C. Writing in a Bilingual Program: the relation of L1 and L2 texts. Tesol Quarterly, v. 16, n. 2, p. 211-228, 1982.

EDELSKY, C. Writing in a Bilingual Program: Habia una vez. Ablex Publishing Corporation, Norwood, 1986.

GROSJEAN, F. Life with two languages - in a Introduction to Bilingualism. New York: Harvard University Press, 1982. 370p.

GUMPERZ, J. I. Discourse strategies. Cambridge: Cambridge University Press, 1982.

HOYOS-ANDRADE, R. E. Algunas de las diferências más llamantivas, de naturaleza fonética-fonológica y morfológica-sintáctica, entre los usos orales e escritos de hablantes de portugués brasileño. Anuario brasileño de estudios hispánicos, v. n.6, p:17-23, 1996.

JORDAN, I. J. Portuguese for Spanish Speakers: A case for contrastive analysis. Hispania, v. 74, n. 3, p. 788-792, 1991.

JUNG, N. M. Eventos de Letramento em uma escola multisseriada de uma comunidade rural bilíngüe (alemão/português). 1997. 174 f. Dissertação (Mestrado em Lingüística 
Aplicada) - Instituto de Estudos da Linguagem, Universidade Estadual de Campinas, Campinas.

KLEIMAN, A. B. Os significados do letramento. Campinas: Mercado de Letras, 1995. LOMBELLO, L.C. Articuladores e elementos de relação na aquisição de português por um falantes de espanhol. Trabalhos em Lingüistica Aplicada. v. 02, p. 87-111, 1983.

LOMBELLO, L.C; EL-DASH, L.G.; BALLEIRO, N.A. Subsídios para a elaboração de material didático para falantes de espanhol. Trabalhos em Lingüística Aplicada. v. 1, p. 117-132, 1983.

MARTINS, L. M. Um Estudo Sociolingüístico da Comunidade de Imigrantes Brasileiros em Santa Rosa del Monday/Paraguai. 1996. Dissertação (Mestrado em Lingüística) Instituto de Estudos da Linguagem, Universidade Estadual de Campinas, Campinas.

MEY, J. L. Whose Language? A study in linguistic pragmatics. John Benjamins Publishing Company, 1985.

MEY, J. L. The societal formation / the text - Curso oferecido no segundo semestre de 1997 no Instituto de Estudos da Linguagem, Universidade Estadual de Campinas, Campinas, mimeo.

MEY, J. L. Pragmatics: in a introduction. Oxford: Blackwell, 1996.

OLSON, D. Language and Literacy: what writing does to language and mind. Annual Rewiew of Applied Linguistic, v.16, p. 3-13, 1996.

PEREIRA, M. C. Naquela Comunidade Rural, Os Adultos Falam "Alemão" e "Brasileiro" Na Escola, As Crianças Aprendem o Português. Um Estudo do Continuum Oral/Escrito em Crianças de Uma Classe Bisseriada. 1999. Tese (Doutorado em Lingüística Aplicada), Instituto de Estudos da Linguagem, Universidade Estadual de Campinas, Campinas.

PERERA, K. Children's writing and reading - analysing classroom language. Basil Blackwell, 1990.

ROMAINE, S. Bilingualism. Oxford: Blackwell Publishers. 1995, 327p.

ROTTAVA, L. A Leitura e a escrita como processos interrelacionados de construção de sentidos em contexto de ensino/aprendizagem de português como L2 para hispano-falantes, 2001, 243 f. Tese (Doutorado em Lingüística Aplicada ao Ensino de Segunda Língua/Língua Estrangeira) - Instituto de Estudos da Linguagem, Universidade Estadual de Campinas, Campinas.

SKUTNABB-KANGAS, T. Multilingualism and the education of minority children. In: SKUTNABB-KANGAS, T.; CUMMINS, J. (Ed.). Minority Education: From Shame to Struggle. Multilingual Matters LTD, 1989.

SKUTNABB-KANGAS, T. Bilingualism or not: the education of minorities. Multilingual Matters LTD, 1981. 270p.

SOARES, M. Letramento - um tema em três gêneros. Belo Horizonte: Autêntica, 1998.

SPOLSKY, B. Sociolinguistics. Oxford: Oxford University Press, 1998, 128p.

STRELOW, C.C.L. Um estudo da interferência do espanhol como primeira língua na aquisição da escrita do português nas séries iniciais, em escola pública estadual de Foz do Iguaçu. (mimeo) Monografia de Especialização em Lingüística em Ensino da Língua Portuguesa - Universidade do Oeste do Estado do Paraná, Foz do Iguaçu.

SWALES, J. Genre analysis - english in academic and research settings. Cambridge: Cambridge Apllied Linguistics, 1990, 260p.

TAKEUCHI, N. N. La semejanza com la lengua materna: tropiezos para el aprendizaje del espanhol. Revista Letras, v. 33, p. 181-185, 1984.

TFOUNI, L.V. Letramento e alfabetização. São Paulo: Editora Cortez, 1995. 
TANNEN, D. Oral and literate strategies in spoken and written narratives. In: Language, v. 58, n.1, p. 1-21, 1982.

THOMAS, J. Cross-cultural pragmatic failure. Applied Linguistics, v. 4, n. 2, p. 91-112, 1983.

TRIBBLE, C. Writing. Oxford: Oxford University Press, 1996, 172p.

VICIANO, V.M. Preposiciones propias portuguesas y españolas. Un estudio contrastivo. Anuario Brasileño de estudios hispánicos, v. 6, p. 25-44, 1996.

WEIRINCH, U. Languages in contact. The Rouge: Mouton, 1968.

ZAMEL, V. Writing one's way into reading. Tesol Quarterly, v.26, n. 3, p. 463-485, 1992.

Anexo

Texto $01-\mathrm{T} 1$

$01 \quad$ Mariazinha é seus avosinhos un dia en uma fazenda viviam un casal de velinhos e una jovinzinha é essa garotinha nâo sé conformava en ser a única pessoa

05 que nâo tinha una amiginha para bincar è ate mesmo pasear a cavalo. entâo a garotinha converso muito com os seu avós é até mesmo começou a faelar de coisas que nei o seu avos avia le dito pasado horas depois a garotinha deu um abaço

10 em seu avos é foi para o seu quarto. é derepente tudo se entâo ela penso.

ja que tudo esta tam calmo porque não sair para dar una volta já que eu nunca esto aconpan hada por que teria medo de sair sosinha.

15 a garotinha começou a caminhar é cantar derepente comecoa un vento muito forte e o tempo comecou a trovejar é mariazinha procupada é distante de sua casa, comecoo a chorar é a pedir cocoro entao ben perto de un matagal mariazinha se

20 escondeu ai entao comecoo a chuver, chuva é mais chuva que não dava mei para sair do matagal entao mariazinha. paso a noite fora de casa. mariazinha. chegou perito de un cemiterio onde avia enterada os seus

25 pais. mariazinha ajohellada e com os seus zolhinhos. cheio de lagrima, comeco a falar pai. é mamâe por que me dechaste. sei que voceis me deixo ums avos que são muito legal é muito carinhosos.so que na

30 vida so tem duas pessoas que pode me far sorir. voceis

sei que é imposivel. so que voceis fazen tamta falta

- Derepente mariazinha sentiu algo muito

35 estraio e oviu una voz que le dizia - mariazinha você deseja tanto ver o seus pais eu poso te fazer velos. so que você vai ter que me prometer una coisa. sim digame é eu tudo farei. você vai ter que passar 35 dias

40 aqui necê cemiterio é cada dia você vai ter que 
colocar flores em cada canto da casa de seus avos. como que mei sei mais one meus avos mora eu estou compretante perdida é por iso mesmo agora que sei que você esta perdida

45 você vai ser a mia prisihoneira. é jamais vera o seus avos mais iso não é justo é por que nâo quando você tinha a canche de estar com seu pais. você não valorisava ê agora você procura verlos porque você mão quer

50 o seus avos que são duas pessoas maravilhosas mariazinha nese intante você tem que valorizar o que você tem é não o que você já perdeu vou te libertar é ate mesmo te mostrar o caminho de volta para a sua casa so que

55 se você q voltar é continuar asin vai acabar sem mei un dos dois.

E por isso que quero que valorise o que você tem asi não eu vou ter que fazer o que eu não quero i assi a mariazinha voteo para casa é acordo é tudo acabou bem

\section{Texto $02-\mathrm{T} 2$}

Foz do Iguacu

01 geralmente eu estou morando aqui en foz a pouco tempo eu gosto do colegas que tenho aqui e tamben das cataratas do Iguacu acho que una coisa muito natural e escrusivamente simples o geito que os jovens curten

05 a vida sain si divertiren masi eu procuro un mei de me devertir de outra forma esenplo se reunir com os amigo un fin de semana en mia casa para esprêsarmos o momento da vida ver um programa bem interesante. e ver o que a vida

10 nos oferece a cada dia, a cidade nen tudo e o mei da agente se divertir porque diversão nâo e somente sair mais e bom agente saber conviver com que a vida nos oferece. Muitas vezes. agente mesmo nâo valorisa o que temos. sempre queremo

15 mais e mais. so que so feliz con a mia familia mesmo sendo proberes. É sempre eu agradeco a Deus en primeiro lugar por que é eles quem crio o cêu e a terra se nâo fosse por ele talves a vente nen esistíriamos. varias

20 pessoas. tem un modo de curtiçâo e craro que somos o que somos. e nâo o que queren os. ser e assim que a vida é e sempre sera. poriso temos que valorisar o que temos é o que somos. A naturesa e dela é nela encontram

$25 \mathrm{O}$ ar fresco e a sobra que geralmente presisamos.

E assim que eu vejo a vida como ela e. O que vai vir eu simplesmente vou aseitar 